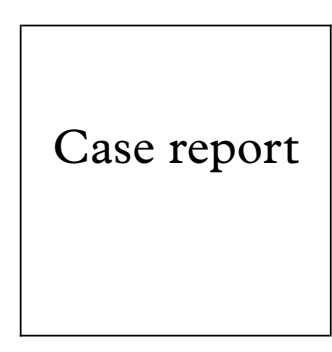

\title{
Extragenital donovanosis in a patient with AIDS
}

\author{
Cornelus J G Sanders
}

A case of extragenital donovanosis in a patient with AIDS is reported from Zimbabwe. Despite the rarity of donovanosis in Zimbabwe it is important that health workers are familiar with this disease since donovanosis increases the risk of HIV transmission and appropriate treatment is often successful even in patients with severe immunodeficiency.

(Sex Transm Inf 1998;74:142-143)

Keywords: donovanosis; Zimbabwe; HIV; AIDS

Donovanosis is a bacterial infection caused by Calymmatobacterium granulomatis, causing lesions that are commonly found on the genitals and in the inguinal regions. The initial lesion is often a papule or nodule which breaks down to form a slowly progressive ulcer which may have flat or hypertrophic borders and starts vegetating causing hypertrophic granulation tissue. The lesions are usually multiple and bleed easily when touched.

Patients with donovanosis tend to present late to healthcare outlets and secondary infection causing regional adenitis may be a common feature. ${ }^{1}$ Extragenital lesions are rare and have been noted in about 3-6\% of cases with predominant involvement of the face, especially nose and lips. ${ }^{2}$

The worldwide distribution of donovanosis is characterised by endemic pockets persisting foremost in Papua New Guinea, Australia, India, South America, and South Africa. Donovanosis increases the risk of HIV transmission and it has been reported in patients with AIDS in Brazil. ${ }^{3}$ To my knowledge no extragenital donovanosis in a patient with AIDS has been reported from Africa.

\section{Case report}

A male patient, 26 years of age, presented to a city health clinic with genital ulcers of more than 6 months' duration and a lesion on the chin which had been present for more than 2 months. He denied any earlier treatment or international travel. He complained of weight loss and non-bloody diarrhoea over 6 weeks.

The patient had generalised lymphadenopathy, oral candida infection, and multidermatomal herpes zoster scars in adjacent thoracic sites on the right chest. Several large vegetating and granulomatous ulcers with elevated borders were seen on the penis which were covered with necrotic slough and were accompanied by tender bilateral inguinal lymphadenopathy. The lesions bled rapidly when touched. On the chin a granulating plaque was present covered with necrotic tissue (Fig 1).

Smears were prepared from several crushed tissue preparations of lesions on the penis and chin and stained with Giemsa. On microscopic examination of smears from both lesions intracellular ovoid bodies with blueish bipolar

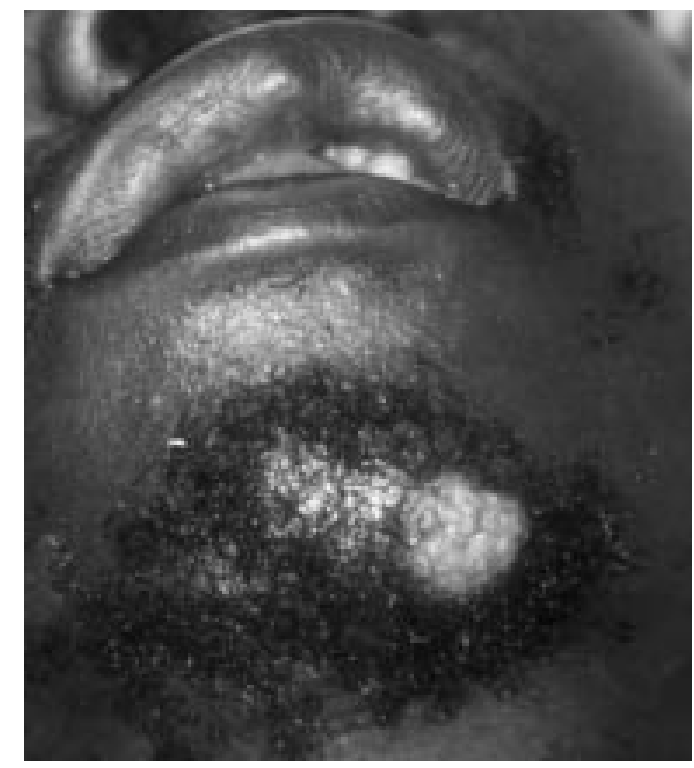

Figure 1 Granulating donovanosis plaque on the chin.

staining (Donovan bodies) were observed in the cytoplasm of large mononuclear cells.

Dark field microscopy, rapid plasma reagin test (Biokit, SA), Treponema pallidum haemagglutination assay (Fujirebio Inc), and a Gram stained smear from the urethra were all negative. After pretest counselling the patient consented to an HIV antibody test (Abbott Laboratories) which was positive.

The patient received oral ketoconazole and tetracycline $500 \mathrm{mg}$ four times daily for 2 weeks and at the end of treatment review the lesions on the penis and chin had healed completely with residual mottled hypopigmentation of the genital (Fig 2).

Partner notification and treatment were not successful.

\section{Discussion}

Patients with donovanosis have been reported in Zimbabwe but in general the disease is considered to be rare. ${ }^{4}$ This seems to be unlike the situation in the eastern part of South Africa where, since the 1980 s, an increased prevalence of donovanosis has been noted. ${ }^{5}$ Our patient denied any international travel and the whereabouts of his sexual partners could not be established. The primary mode of transmission of donovanosis is thought to be through 


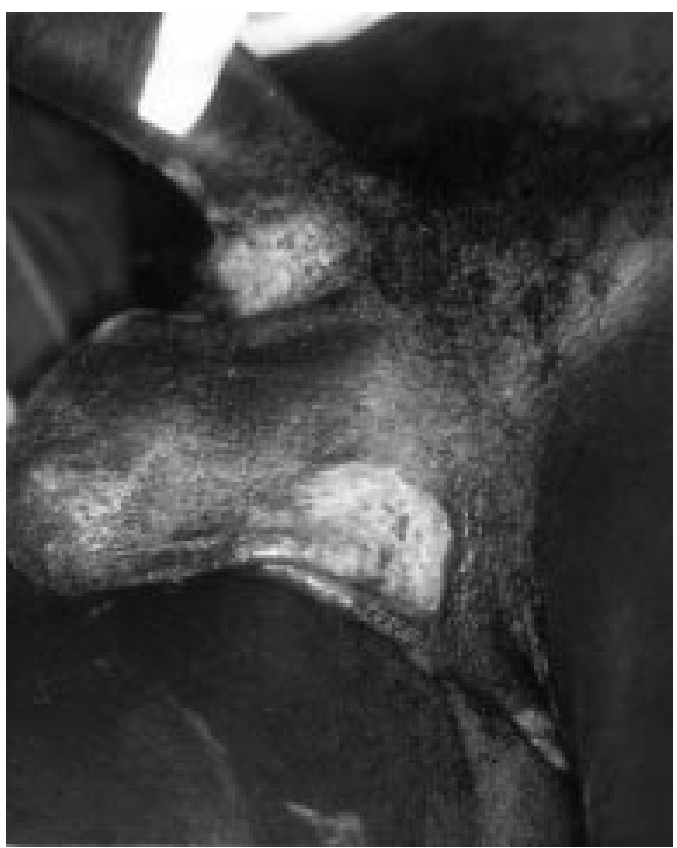

Figure 2 Hypopigmented scars of donovanosis on penis and scrotum.

sexual intercourse although Calymmatobacterium granulomatis has been isolated from faeces. With the available information from this particular patient it remains unclear how or when the infection was acquired.

The patient delay before health care is sought in cases of donovanosis is noteworthy and may be due to the fact that the lesions are often painless and/or patients assuming that symptoms will resolve spontaneously as with, for example, syphilis or herpes simplex infections. ${ }^{1}$

Donovanosis has been associated with an increased risk of HIV transmission, ${ }^{1}$ but since this patient had signs and symptoms compatible with AIDS it is unlikely that his donovanosis episode is related to the acquisition of HIV infection.

Despite the underlying severe immunodeficiency in this patient the response to treatment of his donovanosis infection was excellent which is contrary to the poor response to conventional therapy in patients with AIDS reported from Brazil. ${ }^{3}$ It is imperative to provide appropriate patient counselling pertaining to drug compliance.

Given the increasing migration of people between Zimbabwe and South Africa it is likely that donovanosis may be encountered more frequently in the future. The fact that donovanosis remains restricted to some localised regions, together with the risk of increased HIV transmission in its presence has led to calls for its global eradication. The excellent response to conventional treatment even in the presence of profound immunodeficiency is reassuring in this regard.

1 O'Farrell N. Clinico-epidemiological study of donovanosis in Durban, South Africa. Genitourin Med 1993;69:108-11.

Brigden M, Guard R. Extragenital granuloma inguinale in northern Queensland. Med $尹$ Aust 1980;2:565-70.

3 Richens J. Donovanosis. In: Cox FEG, ed. The Wellcome trust Richens J. Donovanosis. In: Cox FEG, ed. The Wellcome trust
illustrated history of tropical diseases. London: The Wellcome Trust, $96-103$

4 Latif AS, Mason PR, Paraiwe E. The treatment of donovanosis (granuloma inguinale). Sex Transm Dis 1988;15:27-9.

5 O'Farrell N. Trends in reported cases of donovanosis in Durban, South Africa. Genitourin Med 1992;68:366-9. 